\title{
Metastatic Malignant Neoplasm in the Small Intestine
}

National Cancer Institute

\section{Source}

National Cancer Institute. Metastatic Malignant Neoplasm in the Small Intestine. NCI

Thesaurus. Code C7524.

A malignant neoplasm that has spread to the small intestine from another anatomic site. 